\title{
COLOR INHERITANCE IN MAMMALS
}

\author{
IX, The Dog-Many Kinds of White Patterns Found-Albinism Resembles That \\ of Other Mammals in Reducing Red More Than B!ack-Inherit- \\ ance of Black-and-Tan Requires Further Data-Red \\ and Liver Simple Recessives
}

\author{
Sewall Wright \\ Bureau of Animal Industry, Washington, D.C.
}

\begin{tabular}{|c|c|c|}
\hline \multicolumn{3}{|c|}{ SOLID BLACK DOG-TVCEB } \\
\hline $1 a_{1}$ & $\mathrm{R}, \mathrm{r}$ & $\mathrm{R}$-roan \\
\hline $1 a_{2}$ & $\mathrm{~V}, \mathrm{v}$ & $\begin{array}{l}V \text {-piebald (unit factor } \\
\text { uncertain) }\end{array}$ \\
\hline $1 \mathrm{~b}$ & $\mathrm{C}, \mathrm{c}$ & $\begin{array}{l}\text { c-imperfect albino (slate- } \\
\text { brown coat, blue iris, } \\
\text { red pupil) }\end{array}$ \\
\hline $2 a_{1}$ & - & \\
\hline $\begin{array}{l}2 \mathrm{a}_{2} \\
2 \mathrm{a}_{3}\end{array}$ & E,e & e-red (eyes unafícted) \\
\hline & & $\begin{array}{l}\mathrm{b} \text {-liver (brown coat, skin } \\
\text { and eyes) }\end{array}$ \\
\hline $\mathrm{Cla}$ & ficatio & $\begin{array}{l}\text { explained in paper on the } \\
\text { RNAL of HEREDITY, } 8: 373 \text {, } \\
\text { l. }\end{array}$ \\
\hline
\end{tabular}

$\mathrm{T}$ REE are many kinds of white patterns in dogs. There are the common, irregular, piebalds of many breeds; the black eyed whites, such as in Bulldogs; the roans occasionally found among Cocker Spaniels; the spotted Dalmation Coach Dogs; the albinotic Pekinese Spaniels, etc. Barrows and Phillips ${ }^{1}$ find that the blue roans and red roans, in Cocker Spaniels, differ from blacks and reds respectively, by a single dominant factor. 'They also find the piebald pattern to be dominant. Much more work is necessary, however, before the great variations in extent and pattern in piebald dogs may be considered to be understood. Most black eyed whites, as Castle $^{2}$ has suggested, are probably comparable to the black eyed white guinea-pigs and mice in possessing an extreme form of the piebald pattern.
Dogs, with a very irregular, a symmetrical type of piebald pattern, are often wall-eyed according to Pearson, Nettleship and Usher. ${ }^{3}$ Among other breeds they mention in this connection, the Old English Sheep Dog, the Dappled Dachs and the Harlequin Great Dane. The Merled Collies, which they also mention, probably belong in a different category. In them, it does not appear to be an irregular piebald pattern, which has invaded the eye; but a general dilution factor, which reduces red to white, and black to slate blue, affecting the eyes as well as the coat. The piebald pattern may also invade the inner ear, and in some way bring about deafness. Thus Pearson, Nettleship and Usher mention deafness as common among white Bull and Fox Terriers, which are extreme piebalds, but note its absence in whites of several other breeds including Collies and Pekinese Spaniels, where a dilution factor is responsible for the whiteness. This deafness in white dogs, calls to mind the deafness of blue-eyed white cats which was noted by Darwin.

A white, with dark points, is occasionally found among Cocker Spaniels. Barrows and Phillips ${ }^{4}$ find that this is due to a recessive factor, which reduces red to white, but black merely to a slate blue. Whether it also affects the eye, they do not mention. These authors speak of another kind of dilution in Cockers, which they have not tried to analyze. Thus, livers vary from dark

\footnotetext{
' Barrows, W. M. and J. N. Phillips, 1915. Journal Heredity, 6:387-397.

2 Castle, W. E., Genetics and Eugenics, pp. 138-140.

Pearson, K., E. Nettleship and C. H. Usher, 1913. A monograph on albinism in man. Part II, pp. 460-512.

${ }^{4}$ Barrows, W. M. and J. N. Phillips. Loc. cil.
} 
chestnut to a faded liver color, and reds vary from mahogany to lemon. The case of blue Merled Collies has been noted above. The kind of dilution, which has been most thoroughly investigated, is that of the imperfect albinos, which occasionally appear in Pekinese Spaniels. Pearson, Nettleship and Usher describe extensive experiments with them.

\section{ALBINO PEKINESE SPANIELS}

Their albinos came from a stock of red Pekinese. Most of them were not complete albinos, but were slightly tinted with cream color. The skin was pink, the iris pale blue, and the pupil red in some lights. The coat was often distinctly colored, in the puppies, with a dull brown color, which might show a distinct piebald pattern. Granular pigment was present in these puppies, but in the adults only traces of diffuse pigment could be found, as a rule. This change in color is parallel to a change in the normal red Pekinese Spaniels, whose coats are brown, tipped with black, as puppies, but turn red later, only the face and scattered hairs on the back retaining the dark color. The mode of inheritance seems clearly that of a single recessive factor. The authors are disposed to question any Mendelian interpretation, but this is largely because they consider the piebald pattern, which appeared irregularly through their experiments, as connected with albinism, and because of complications, due to the introduction into the experiments of a second well known Mendelian factor: that in which blacks are dominant over reds.

Although coming from a colored stock, the albinos bred true at once, (except for minor variations). Albino by albino produced 66 albinos, of which 11 were decidedly brown as puppies, and 2 were recognizable piebalds. Red parents, both of which were known to carry albinism, from knowledge of their parents or offspring, produced 32 red, and 14 albino puppies, about as expected, allowing for matings of their type which were unrecognized because no albinos were produced. Red by albino produced only 57 reds in 16 litters, and 5 reds, 4 albinos in 2 other litters. Most of the reds were evidently homozygous. Some of the albino Pekinese were crossed with black Pomeranians. As these albinos came from red stock, this cross would be expected to involve at least two Mendelian factors; that by which blacks differ from reds, and that by which intense colored dogs differ from albinos. In $F_{1}$ all of the puppies were intense, and most of them black. Two of the 17 were called chocolate, which indicates that the Pomeranians were not all homozygous black. Some of the black offspring (EeCc) were crossed together and produced 6 blacks (with white patches), 1 red sable, like a normal Pekinese, 1 normal albino and 1 permanently slatebrown or "lilac" puppy, with the eyes of an albino. One need have little hesitation is surmising that this "lilac" is the albino form of black (Ecc) where the usual Pekinese albino is the albino form of red (eecc). A back cross of $F_{1}$ black with Pekinese albino likewise produced the four expected classes. There were 10. blacks, 2 golden sables, 1 "lilac," and 2 usual albinos (one of which showed a red streak on its back). The ratio, it is true, is very aberrant; such a large excess of blacks should be produced only once in a thousand times, but taking the evidence as a whole, there seems little reason for doubting that merely two unit Mendelian factors are involved aside from the factor or factors for the piebald pattern. It has been suggested above that the albino factor which reduces red to white merely reduces black to slate-brown. This is in harmony with the brown color of Pekinese albinos at the time of life in which normal reds show much black pigment. It is also thoroughly in harmony with the effects of imperfect albinism in other mammals. The same difference in the threshholds for black and red, with respect to albinism, have been noted in previous papers in the discussion of red-eyed dilute guinea-pigs and rats, and Himalayan rabbits. A similar phenomenon is found in man.

Among factors of class 2, it seems well established that all grades of red differ 
from black and liver by a recessive unit factor. Little ${ }^{5}$ obtained satisfactory figures demonstrating this point in Pointers, and Barrows and Phillips ${ }^{6}$ confirm it in Cocker Spaniels. The presence of this factor difference between red Pekinese and black Pomeranians has just been noted.

This, however, leaves uncertain the genetic relations of the various kinds of mixtures of black and yellow. The common color of Collies is a sort of sooty yellow; in Great Danes, Bull Terriers and other breeds there is a brindle pattern and many breeds are characterized by the black-and-tan pattern in which the feet, belly, and parts of the head are tan or yellow, the rest of the coat being black. A similar pattern is found among the wild canidae.

\section{THE TRICOLOR PATTERN}

In many breeds both the piebald and the black-and-tan pattern are present together. The result is a tricolor. The mode of inheritance of tricolor is of special interest because it was the character in Bassett hounds, which was chosen by Galton ${ }^{7}$ in his pioneer investigations of the laws of heredity. The tricolor Bassett hounds continually throw bicolor lemon and white, and vice versa.

Galton demonstrated heredity in this case, and showed that his law of ancestral heredity would fit the results satisfactorily. This law claims only to describe the average results in a dog population mated at random as regards color and is not intended to apply to particular cases. As Castle ${ }^{8}$ has pointed out, no simple Mendelian ratios are to be expected in this case, in which the occurrence of bicolors depends on the arrangement of two independent, fluctuating patterns. Castle compared the case with that of tricolor guineapigs, which result from the combination of the piebald and tortoise shell pat- terns, with genetic results as confusing to follow as the Bassett hounds. Hagedoorn ${ }^{9}$ pointed out that the blackand-tan pattern in dogs is a more symmetrical pattern than the tortoise of guinea-pigs, but in the main accepted Castle's view. Ibsen ${ }^{10}$ pointed out that Bassetts have a reduced type of the black-and-tan pattern, like that of Airedales, in which there is only a blanket of black on the back, leaving the head yellow. As the white of the piebald pattern affects the back before the head, lemon and white is more apt to be! produced than black and white on reduction in the number of colored spots. It is clear that the mode of inheritance of tricolor can best be solved by studying the heredity of the piebald and the black-and-tan patterns separately.

Barrows and Phillips ${ }^{11}$ identify the pattern of black-and-tans with that of liver-and-tans, and of red-and-lemons. They state that a recessive factor is responsible for the production of these "bicolors" from blacks, livers, and reds respectively. A priori the indentification of the patterns of black-and-tans and liver-and-tans, seems probable enough, but red-and-tan seems to involve a different kind of factor. The first two involve variations in extension of a dark color, and therefore involve factors of class 2 while the last is a pattern of intensity which would seem to fall in class 1 .

It has been noted that in the rodents and in cats there is a tendency for the processes of producing color in general (involving enzyme 1) and of producing black (involving enzyme II) to be weak in the same parts of the coat. Thus the patterns of intensity of color (particularly of yellow) and of extension of black, tend to be similar, although brought out by wholly independent Mendelian factors. For example yellowbellied gray mice differ from solid grays for a wholly different reason from that

${ }^{5}$ Little, C. C., $1914 . \quad J o u$. Jal Heredity, 5:244-248.

- Barrows, W. M. and J. N. Phillips. Loc. cit.

${ }^{7}$ Galton, F., 1897. Proc. Roy. Soc. Lond., 61.

${ }^{8}$ Castle, W. E., 1912. Amer. Nal., 46:437-440.

'Hagedoorn, A., 1912. Amer. Nat., 46:682.

10 Ibsen, H. L., 1916. Genetics, 1:367-376.

1 Barrows, W. E. and J. N. Phillips. Loc. cit. 
in which white-bellied yellows differ from solid yellows. It should be added, however, that factors are known which produce effects as if of both class 1 and class 2 , and the bicolor pattern of dogs may be one of these. Further data would be very welcome.

The relation of black-and-tan to black and to red is another question on which further data is necessary. There are three possibilities. The recessive factor by which the black-and-tan differs from black may be identical with factor e by which red differs from black. In this case, a subsidiary factor or factors must be supposed to modify a red into a black-and-tan. Second, the black-and$\tan$ pattern may be due to an allelomorph of factors $\mathrm{E}$ and $\mathrm{e}$, intermediate in effects. Third, it may be due to a factor independent of the extension series as supposed by Barrows and Phillips. ${ }^{11}$ Ibsen quotes Barton to the effect that red by red may occasionally produce black-and-tan, and that black-and-tan by black-and-tan may occasionally produce red. Hagedoorn is also quoted, as stating that red may be dominant over black-andtan. This evidence is easily harmonized with the first hypothesis above, but not so easily with the second and third.
If the last proves correct, it must be supposed that reds are of two kinds, some dominant over black, some recessive.

\section{LIVER COLOR IN DOGS}

Perhaps the best established factor in dogs is one of class $2 \mathrm{~b}$. Lang ${ }^{12}$ obtained indications, in a particular cross, that brown is recessive to black. Little $^{13}$ thoroughly confirmed this conclusion in Pointer dogs, and Barrows and Phillips ${ }^{14}$ in Cocker Spaniels. This factor converts all black pigment in skin, fur and eyes to brown, thus changing solid black dogs to solid browns or "livers"; black-and-tans to liver-and-tans; and reds with black nose, ears and eyes to reds with brown nose, ears and eyes. Barrows and Phillips suggest further that red is reduced to lemon, but this seems inconsistent with their statement that both reds and lemons may have either black or brown points. Little speaks of yellows with brown points as somewhat duller than those with black points, but this may be due merely to reduction of a slight black sootiness in the fur to brown. On the whole there seems little reason for doubting that this factor may be compared" with the chocolate-brown variations of rodents.

\section{Longevity in Lily Pollen}

During the season of 1916 I made a large number of crosses among my various lilies and wishing to use some of the earlier kinds with the later, I saved in small envelopes, the pollen of all the best early sorts to use later as later kinds bloomed. I found most of the pollen was good for two or three months saved in this way. Wishing to know if the pollen of some of the late ones might be kept over to use on the early ones in spring, I saved it from the $L$. auratum, wrapped in two or three sheets of paraffine paper and kept in a warm, dry place. Last spring I opened this and used it on a flower of Lilium martagon. The first application was a success and a good capsule of seed was obtained, but later this was tried on a lot of flowers of other lilies with no results. Only when the pollen was first exposed to the air was it potent. Care was taken to remove the anthers before the flower had opened and to cover well as soon as the old pollen had been applied. Had the pollen been divided and kept in separate envelopes so that it was used at once when first exposed to the air, I believe more capsules would have been fertilized. Charlotte, Vt.

12 Lang, A., 1910. Zeit. Abst. Ver., 3:1-33.

${ }^{13}$ Little, C. C. Loc. cit.

14 Barrows, W. M. and J. N. Phillips. Loc. cit. 